\title{
Optimising the Contribution of Design to Innovation Performance in Indian SMEs - What roles for Culture, Tradition, Policy and Skills?
}

\section{Authors: Professor Simon Bolton ${ }^{1}$, Dr Lawrence Green² and Bhavin Kothari}

\section{ABSTRACT}

This paper examines the historic growth and development of the design sector in India, and evaluates the potential of the industry to contribute to innovation performance as the country's manufacturing sector continues its expansion. Via a comparative analysis of design policies in advanced economies and those in India, and an evaluation of the performance of design promotional initiatives, the paper identifies lessons that might be incorporated sensitively into the future elaboration of Indian design policy. The paper concludes that design inputs can contribute to both social and economic development (and to innovation performance in both traditional craft and hi-tech manufacturing). However, it also argues that policy to support intelligent growth, diffusion and take-up of design must be attuned to both qualitative issues of culture, diversity and tradition, and to 'harder' issues of location, infrastructure, skills, investment and demandi.

Professor Simon Bolton is Chair of Innovation and Associate Dean in Employability and Enterprise, Faculty of Arts and Science at Edge Hill University.

Dr Lawrence Green is Associate Professor and Director of Research in Art and Design in the Faculty of the Arts, Design and Media at Birmingham City University. He is also co-director of the Strategic Creativity Research Lab

Professor Bhavin Kothari is Associate Senior Faculty within the Strategic Design Management discipline at the National Institute of Design (NID). He is mentor in Design Management and Intellectual Property at NID

\footnotetext{
${ }^{182}$ Corresponding Authors: Simon Bolton, Edge Hill University, St Helens Road, Ormskirk, Lancashire, L39 4QP (boltons@edgehill.ac.uk); Lawrence Green (Lawrence.green@bcu.ac.uk) Birmingham City University, Parkside, Cardigan St, Birmingham, B4 7BD
} 


\section{INTRODUCTION}

The relationship between creativity, design and innovation has received increasing scrutiny in both academic and policy circles throughout the past decade. In a discussion triggered by the Cox report (1-10), various strands of thinking and enquiry have emerged. Building from the long acknowledged link between investment in innovation and growth and competitiveness, several commentators have alluded to the strategic role of design in organisational re-structuring and positioning (Brown 84-93; Furniss 18-23). Others have investigated the theme of design methodologies and approaches and their transferability to non-design settings (Green, Cox and Bitard 268-288), and yet more have addressed the role of design in raising the performance of small and medium-sized enterprises (Moultrie, Clarkson and Probert 184-216). Whilst this research and has achieved considerable impact on industrial policy-making and firm responses to globalising markets, it is notable that almost all has been undertaken in highly advanced European and North American economies.

This paper sets out to redress the balance with an investigation of the role of design and design practitioners in enhancing the performance of micro-enterprises and SMEs in the Indian context (ISMEs). Growth rates in the sub-continent have reached enviable proportions in recent years, and at least some of this success can be credited to the design policies and design support agencies that have targeted the improvement of innovation and new product development performance in the SME-based advanced manufacturing sector. The paper builds from a descriptive history of design support policy in both the West (particularly the UK) and India notably via the visionary inception in the 1950s of the National Institute of Design. It then moves to examine - via analysis of interview data with key design actors and examples of successful innovating manufacturers - the ways in which design methods, approaches, tools and inputs can promote performance and increase competitive advantage. The paper will examine the crossapplicability of design/creativity theories developed in non-South-Asian contexts, and identify the particularities of the contribution of Indian design expertise in generating success for indigenous manufacturing businesses. We focus in particular on the role of culture and cultural and locational diversity in India, and examine how these factors will shape opportunities for, and the role of, design as India's manufacturing and economic growth continues to unfold. We also focus on craft industries and existing technologies (often low-cost technologies) to evaluate the ways in which design can support both economic and social development.

\section{Core Aims and Structure of the Paper}

The paper commences by examining the growing body of evidence and commentary relating to the contribution of the creative industries - especially the design sector - to the innovation 
performance of firms and national economies. It moves on to explore trajectories in policy that have been elaborated as a means of supporting and fostering design, and provides examples and analysis of design promotion initiatives from across the globe. The paper then addresses the ways in which design can be used to leverage competitiveness, and here we address the core issues and questions upon which the study is founded, specificallyi:

- How and in what ways do the creative industries $(\mathrm{Cl})$ and creative practitioners contribute to innovation performance in Indian SMEs (ISMEs), and what is the role of design promotion initiatives in delivering enhanced competitiveness?

- What are the implications of cultural diversity, demographics and regional identity for design-enabled innovation in ISMEs: how is urbanization impacting on the evolution of design ecosystems, and how can design increase capacity to exploit low-cost technologies, craft methods and traditional expertise?

In closing sections, the paper sets out some reflections on both empirical and theoretical components of the study, and considers challenges for the future optimization of design in India. The paper concludes with a review of the factors that are shaping the contribution of design to innovation performance in Indian enterprises, and sets-out suggestions for appropriate support policy. Social, economic and industrial development can be aided by intelligent and sensitive application of smart design, though policies to promote such design must be guided by acknowledgement of history, culture and changing realities. In short, further design-related development in India will be required to take account of:

- Implications of the diversity of regional cultures and identities for the role and application of design in Indian ISMEs

- The influence of urbanisation on design, development and production eco-systems in India

- Barriers to the adoption and use of design (especially those that hamper delivery of innovation performance in Indian ISMEs)

- Changing practices and applications of (and opportunities for) design in traditional and hitech manufacturing

\section{CREATIVE INDUSTRIES AND INNOVATION PERFORMANCE}

Today the creative industries $(\mathrm{Cl})$ sit at the centre of economic development and growth in both the developed and developing world. They constitute a growing proportion of the economic output and employment of many advanced nations, with contributions to GDP ranging from $2 \%$ to $6 \%$, depending, of course, on definitions deployed, and sectors under study (CISAC 1-67). 
Mapping the importance of the Cls to national economic output was pioneered in the late 1990s in the UK, when the Government's Department of Culture, Media and Sport (DCMS) published the "Creative Industries Mapping Document 1998". The potential of the Cls to become an engine for economic development and growth was quickly recognised by other national governments, many of which subsequently replicated the format of the UK study. Hong Kong, New Zealand, Singapore and Australia initiated analogous exercises to facilitate measurement of the size and contribution of the creative economy within their own territories (CISAC 1-67), and each confirmed UK findings of substantial impacts at regional, sector and national levels. At around the same time, and from a sociological perspective, Florida (1-18) contributed ground-breaking work on the links between thriving, cosmopolitan cities and rates of creative enterprise, social tolerance and cultural activity. Florida's studies complemented those of national economic research agencies, and pointed to key factors in regional/city-based socio-cultural and creative development.

The Creative Industries were defined by the UK DCMS in 2001 (5) as "those...which have their origin in individual creativity, skill and talent and which have a potential for wealth and job creation through the generation and exploitation of intellectual property". It is this definition that is deployed in this paper. We also allude (albeit in an indirect way) to the concept of national systems of innovation, and the factors that affect national performance. Here we employ Lundvall's notion (119) that national innovation systems are characterized by "the elements and relationships which interact in the production, diffusion and use of new, and economically useful, knowledge ... and are either located within or rooted inside the borders of a nation state."

UK mapping has generated valuable data that has evidenced the contribution of the Cls to the UK economy, and has helped to fuel the development and growth of the creative sector. The recent 'Creative Industries Economic Estimates' study from the UK Government (1-46), helps to illustrate the importance of the Cls to economic performance. From an employment perspective the Creative Economy (CE) had, by 2013, generated $2.62 \mathrm{~m}$ jobs: a figure that equates to 1 in 12 of all UK jobs. Between 1997 and 2013 employment in the CE increased from $1.81 \mathrm{~m}$ to $2.62 \mathrm{~m}$, equivalent to a rise of $2.3 \%$ year-on-year.

The potential value of the Cls has not been missed by developing countries. Commentators, for example, UNCTAD (1-14) ; Throsby (66-71) have argued that the value of the Cls to developing nations is linked to their ability to (a) stimulate cultural and social development, such as national identity, social cohesion, preservation of common values and collective institutions, and (b) provide a tool for economic growth based on the potential to create employment, generate incomes, earn export revenues and alleviate poverty.

The strength of the data generated by the UK government's CI Mapping exercises highlights a key 
dilemma for India. Multiple organisations in the country draw attention to the fact that there is a scarcity of economic data re: the Cls (CISAC 24). This shortage of reliable statistics has resulted in limited systematic analysis and an inability to fully determine the size and contribution of the creative sectors to the Indian economy as a whole. A further underlying challenge resides in weakness in legislative frameworks, in particular, enforcement of copyright (a weakness that has largely been addressed in Western contexts).

These apparent problems are perhaps surprising given the importance, diffusion and ubiquity of Indian culture and its creative products. The Bollywood film industry is a useful case in point. In 2009, Bollywood produced 1,200 feature-length films, compared with 987 productions (in video format) in Nigeria and 694 major films in the United States (UNESCO 9-91). The opportunity for both category and sector growth in the Cls has been emphasized by the Indian National Skill Development Corporation. This body states that out of 21 high-growth sectors with employment expansion opportunities in India, only four are currently in the creative sector domain (textiles \& garments; gems and jewellery; handlooms \& handicrafts; and media/entertainment/ broadcasting/content creation and animation). Clearly then, there is strong potential for growth throughout the Cls, and the potential contribution of design to the innovation performance of Indian SMEs (both within and outside the $\mathrm{Cl}$ sector) is substantial.

\section{THE PROMOTION OF DESIGN: DESIGNING POLICY FOR COMPETITIVENESS AND BEYOND}

Heskett (71-84) identified a robust link between national competitive performance and the prevalence and quality of design activity. He argues that (effective) design policy enables the promotion and creative use and development of technologies, and that this demonstrably results in the delivery of "economic advantage by enhancing national competitiveness." Design and product innovation have long been recognized as key tools for economic growth by progressive governments (this is notable, for example, in Japan, the UK and Germany). A defining characteristic of design - the application of creativity to connect technology and the user - creates a potential for design to act as a critical instrument in fostering and facilitating economic growth at regional and national levels. Acknowledging and underscoring this potential, the achievement of enhanced competitiveness is one of the main rationales that drives the creation and implementation of design promotion policies by governments. National technology and innovation policies have traditionally been the drivers for the creation of design policies and promotion activities. Indeed, Choi (unpublished PhD thesis, Lancaster) suggests that the most competitive countries "are working to improve awareness of the importance of design, increasing global competitiveness, and raising people's quality of life". According to the World Economic Forum Competitiveness index in $2006-2007$ (3), $77 \%$ of countries at the highest stage of development 
have had (or retain) design promotion programmes in place. This compares with only $4 \%$ of countries located at the lowest stage.

The burgeoning of design policies (typically emerging from industrial policy), that have endorsed the benefits of using design and promoted its role in delivering economic growth and competitive export performance (Do Patrocinio unpublished PhD thesis, Cranfield), has been fuelled in part by (1) the availability of low-cost technologies for production (Velloso 599) and (2) the Cl's ability to exploit these. UNCTAD (5-8) argues that these factors have positively impacted on the world economy (especially in developing nations) in the period up to 2008, and - via analysis of comparative international growth rates - it may be argued that this trend has continued to date. There has also been a clear correlation between the use of design policies and export-oriented economic strategies. Another emerging trend is the development of design policies that are focused on more than the creation of economic growth and development: some such policy is now oriented firmly towards the improvement of life for citizens. Lee (16) advocated this shift in favour of more social dimensions by suggesting that effective design policies "must combine economics, society and the culture of a nation; ranging from increasing exports and nation's competitiveness to a higher quality of life for its citizens." This movement is reflected in the adoption of strategies with programmatic and broader policy level focus (as opposed to isolated programmes that centre on the linkage of design to industrial policy). The former highlight a more inclusive direction for design policy, one that is targeted at improving national infrastructures, services and systems.

Still relevant today are Bonsiepe's insights re: the development and implementation of design policies in developing countries. Bonsiepe (1-22) highlighted the potential risks of considering craft design as a forerunner to industrial design in developing countries with lower levels technological infrastructure. He has maintained his argument that it is "misleading" to consider "industrialization as... a way of overcoming arts and crafts manufacturing methods". He states that this type of approach often leads to a "self-inflicted cut-off from development possibilities". In his pioneering work, Bonsiepe established a series of general rules to support the development and implementation of design policies in developing countries:

- Design should be oriented to available technology and demand;

- Local assessment standards for design should be established;

- Priorities should be based on social benefits and multiplier effects;

- Imported design (and 'know how' and methodologies) should be adapted to local conditions;

- The highest priority should be assigned to training and logistical support.

These principles retain considerable power, especially when viewed in the context of India's 
national design policy needs: the latter require the encompassing of rural, peri-urban and metropolitan localities and population centres. Indeed, the case of India highlights the importance of engaging with global trends, whilst pointing strongly to the need to tailor policies to support national, regional and local cultures and identities. A 'one-size-fits-all' strategy simply cannot work in such complex settings. Alpay Er (293-307) argued for the need for policies that take into account different development stages within a single country: it can therefore be argued that "national context" is paramount in the shaping of design policies" (Choi unpublished PhD Thesis, Lancaster), and that context is influenced by a nation's culture and identity. Potential national design policies are further complicated by the need to simultaneously deal with differing stages of design maturity across the country.

It is clear that India is afforded an opportunity to learn from the experiences of others - both nations and design organisations - with respect to policy design, and the uses for which policy might be employed. However, caution is required. As Maguire and Woodham () have argued, ineffective infrastructure, education and communication are factors that can lead to failure in the delivery and implementation of design policies. Infrastructure failure has been attributed to poor national distribution of design services, complex delivery structures, duplication of activities between national agencies, saturation of business support programmes and ineffective evaluation processes. Educational failures are deemed to result in an under-skilled workforce and failure to address a lack of capability. This can impact on the growth of urban design-industry eco-systems and constrain development of successful (and exemplar) design-based companies and services. Communication failures can result in mixed-messages, weak diffusion of initiatives, and inability to learn (and to diffuse learning) from both success and challenge cases. So, whilst design policy might deliver manifest and manifold benefits, the design of such policy requires sensitivity to: current and evolving needs; existing technologies and skills levels; regional contexts, cultures and industry profiles; communication and diffusion mechanisms; and, the availability and quality of techno-social infrastructures.

\section{DESIGN AS TOOL FOR COMPETITIVENESS}

Design as a tool for delivering national competitiveness is not new to India. The 1950's was a period of re-evaluation and rebuilding in a newly independent nation. Tasked with rebuilding the country, (and balancing age old traditions with modern technology and ideas), the Government of India, with the assistance of the Ford Foundation and the Sarabhai family, sought recommendations on a programme of training in design that would (a) serve as an aid to small industries, and (b) halt a perceived deterioration in the design and quality of consumer goods. Leading designers Charles and Ray Eames were approached for their advice, and their contribution (along with that of other leading designers and policy actors) resulted in the 'India 
Report' (1958), a publication that led to the birth of a coordinated approach to design training in India. The report recommended a problem-solving design consciousness that linked learning with actual experience: there was an expectation that such an approach would constitute a bridge between tradition and modernity. The report was underpinned by the values and qualities of a 'good life', and recommended that 'there be close scrutiny of those elements that make up a [desirable] standard of living'. It also advised exploration of the meaning and utility of 'the existing symbols of India'. On the basis of the recommendations of the India Report, the Government established in 1961 (at Ahmedabad), the National Design Institute. This was to be an autonomous body under the aegis of the Department of Industrial Policy and Promotion and the Ministry of Commerce and Industries. Now known as the National Institute of Design, the organization has expanded with additional campuses in Gandhinagar and Bengaluru. There are currently proposals for the initiation of four further branches - a testament to India's commitment to the development of design education.

Historically, Indian companies have relied (in large measure) on designs from external sources. According to the Confederation of Indian Industry (CII, 2009), such companies would employ inhouse designers too, but largely as translators of design, and as 'modifiers' of plans to meet with existing production capabilities and local user needs. This approach has arguably restricted the growth and development of design within Indian industry. The 'import' situation continues, to this day, though it is common now for both novel and adaptive design activities in India to be undertaken by in-house designers. In-house design departments are prevalent in companies in the consumer products, automobiles, fashion and accessories, software and hardware, and furniture design sectors. Many young designers elect to work in such in-house departments as they perceive benefits in terms of predictable hours, career paths, and opportunities for structure and collaboration. Whilst individual choices are understandable, it can be argued that the emphasis on relatively minor modification activities has contributed to limitation on the understanding of how design might be deployed strategically within organisations (Brown, 2009). Many SME's perceive design to be complex and challenging, particularly when it is recommended as a strategic tool to assist in responding to business challenges. This is problematic: it is precisely in this role that design might deliver greatest value to growth- and new product-oriented smaller firms (Bolton and Green, 2015).

There are parallels in research with UK SMEs that indicate that SMEs experience greater levels of uncertainty and risk-aversion when working on strategic front-end innovation activities (see Figure 1: concept development stage (CDS) activities $A$ and $B$ ): such firms report greater confidence when processing rear-end incremental product development activities (Figure 1: CDS activities $\mathrm{E}$ and $F$ ). In relation to front end activities (A-C) uncertainty can be attributed to several factors: (i) lack of resources and expertise, (ii) insufficient end-user contact, (iii) the adoption of low 
risk/incremental strategies, (iv) over familiarity with served markets, and (v) irregular engagement in 'genuinely new' product development. Clearly then, there are factors shared across Indian and UK SMEs. Further, for both UK and Indian SMEs, application of design may not constitute a high priority in the face of other pressing business imperatives. As the Design Council (2012) suggests, "design can often seem like something to explore when times are good, not when resources are squeezed."

As noted above, the power of design is important to developing countries as it founded on an ability to connect technology, creativity and the user. Many in the Cls have realized this potential and have learned how to exploit low-cost technologies. The capacity of design to foster and facilitate change - in combination with its potential as a tool to assimilate technological advancement for quality of life and societal improvement - make it a forceful potential driver for both social development and economic advancement in developing countries. These are recurring objectives in India, ones that lie at the heart of the India Report of 1958.

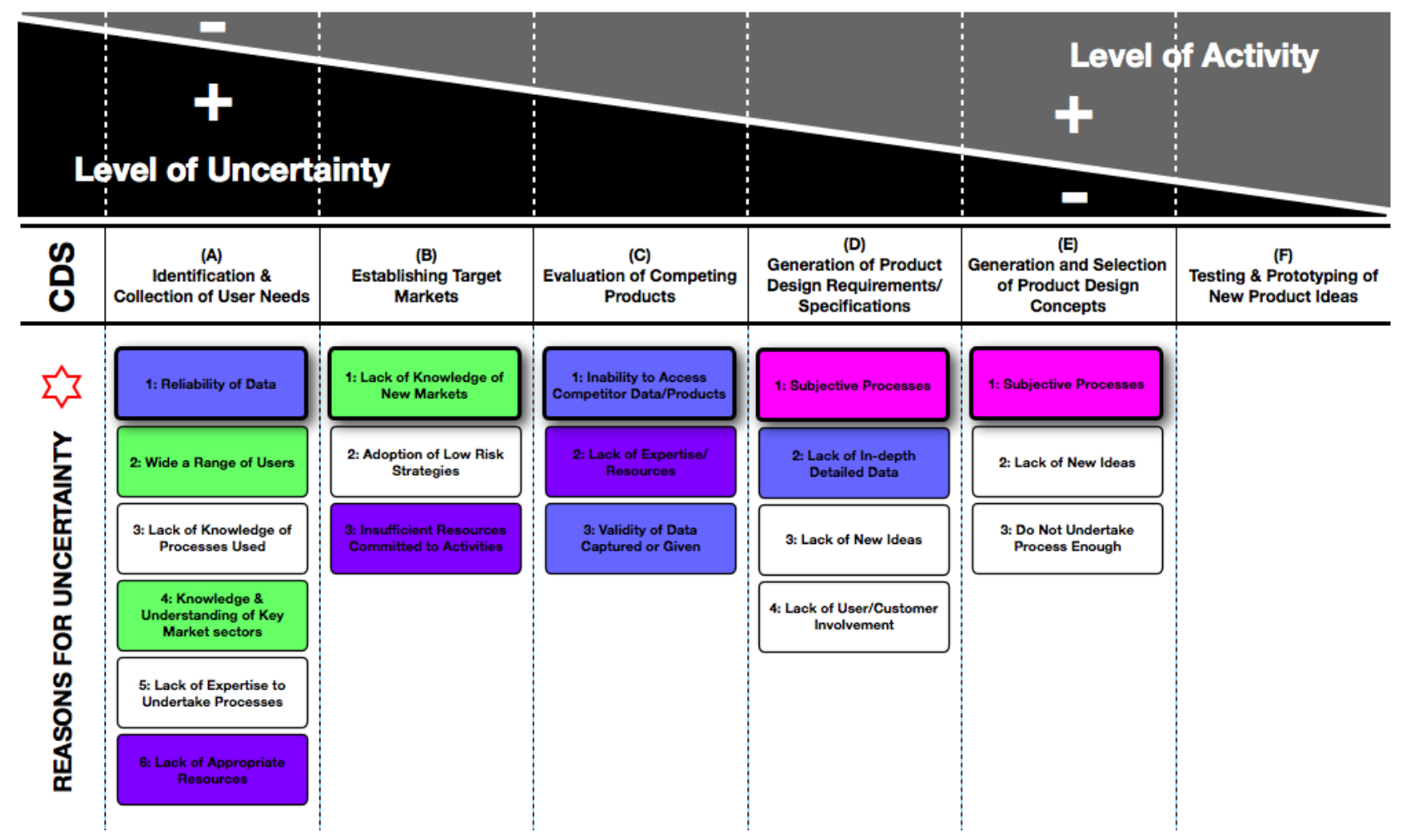

Figure 1: Levels of Uncertainty in SME Front-end Innovation Activities (Bolton, 2013)

Moreover, design can be used specifically to address "technology-stagnation" in developing countries (IDC, 1989). This is of particular importance given the conventional reliance of Indian companies on imported design and local adaptation. As Indian industry produces greater numbers 
of original products, the role of design and designers will be become more important. The recent inception of the 'India Design Mark' - a celebration of good design - is an initiative that was launched to promote excellence in indigenous designiii. The adoption of the Mark by the India Design Council attests to the raised profile of design in the county, and authorities are eager to see design embedded as (a) a tool for national competitiveness, and (b) a differentiator of exported products and services. Design can also be linked to key Indian export sectors, both traditional and evolving. Such sectors are broad and varied and include, for example: handicrafts, leather items and hand tools; small industry turnkey projects; IT solutions; and, provision of relief supplies (for the UN etc.)

\section{OPPORTUNITIES AND CHALLENGES}

As we note earlier, the adoption and performance of design can be adversely affected by ineffective infrastructure, education and communication: individually and combined, these factors can undermine the efficacy of design policies (Maguire \& Woodham, 1997). To offset potential challenges, Governments (both developed and developing) need to create and maintain a positive and conducive environment for design, and an appropriate supporting infrastructure. Where these factors are in play, design will be well-placed to contribute to the innovation performance of SMEs (CII), 2012). An opportunity exists for Governments to integrate design in core areas of its own service provision, and thus test ideas and provide exemplars - such an approach has been adopted in the UK and elsewhere with the involvement of designers in service development (Arawati, Sunita and Kandampully). The approach aids in optimizing investments, and in ensuring that services are aligned with citizen's needs (CII, 2012, p.105).

An example of good practice resides in the Design Clinic Scheme, an initiative conceived and operated by the Indian Ministry of Micro, Small and Medium Scale enterprises and National Institute of Design (Development Commissioner, 2010). The objectives of the Design Clinic scheme are to enhance industry understanding and application of design and innovation, promote design as a value-adding activity, and, to integrate it into the mainstream business and industrial processes of SME's. The scheme addresses a diverse range of products from the very simple to the technically complex, and focuses on micro and small and medium enterprises (MSMEs)' that are vulnerable to business, political or social change.

The Clinic scheme was founded on the basis of lessons from the UK Design Council's 'Designing Demand' programme (Design Council, 2012). The purpose of the latter has been to build capabilities in UK SMEs, and to understand how such firms can use design strategically and effectively within their business. Driven by a 'learning by doing' approach, the programme has successfully enabled businesses to identify how design best meets their aims. It has also 
supported them in implementing tangible design-enabled projects that are configured to pursue business objectives. The Indian and UK schemes share a common goal of aiding SME manufacturing firms to ascend the value chain: however, despite visible success, a majority of Indian and UK MSMEs still use design only sparingly. This, of course, prompts the question, 'why is this the case'? Analysis of the literature surfaces three key challenges to the adoption of design: ineffective communication (Chiu, 2002); lack of capabilities; and, business strategies that are risk averse (Design Council, 2011). CII (2012) indicates that the biggest barrier for Indian businesses in embracing design for innovation is a lack of information. The Confederation finds that businesses are rarely aware of the potential offered by design disciplines: this is connected with a scarcity of economic/performance data and an inability to communicate benefits.

A lack of capability and skilled workers is a fundamental challenge for India. The Indian Design Council (IDC, 1989) indicates that design education at school and university level has been recognized as a prime factor in sustaining high quality design at regional and national level. Currently in India there is poor availability of skilled design professionals. This situation is created in part by the previously stated over-reliance (especially in engineering production) on foreign technical know-how and design. The failure to sufficiently develop indigenous design and development capabilities is caused by lack of investment in design skills - as a result, the Indian market continues to remain flooded with foreign products that in many cases do not meet the aspirations or needs of local consumers (CII, 2012). A shortfall in quality and highly-qualified design faculty also exists, and this is both hindering the training of design graduates, and the development of new design institutions in India. There is a common sentiment within the design industry that current design graduates are not well-equipped as a result of a disconnection between syllabi and industry design trends - design education cannot keep-up with developments in practice (Furniss, 2015). The design industry is also in need of support to develop the design management skills of its existing practitioners (Topalian, 2002). From an industry perspective, it is also evident that there is a language and communication problem: business frequently fails to speak the language of design, and designers are unable to connect adequately with business concepts and needs: it is imperative that designers communicate in a language that executives understand (and vice versa) (Bolton and Green, 2015).

According to the Korean Institute of Design Promotion (KIDP, 2008), design-related investment in India is amongst the lowest in the world: design is evidently an underused activity in most Indian businesses, and one that is frequently perceived as an expense item reserved for large companies. Traditional Indian SMEs have typically relied on cost innovation strategies, as investments in research have been outwith their capabilities. There is evidence that Indian SME's rely very little on R\&D for innovation: both formal and informal manufacturing sectors demonstrate very modest connection with design (CII, 2012). The development of in-house, adaptive, design capabilities is arguably a poor short term investment, and symptomatic of a lack of willingness 
among entrepreneurs to develop markets via the introduction of genuinely novel and innovative product ideas. Product innovation is not typically seen as a vital concern in Indian industry, thus design rarely achieves priority status. Whilst the situation is not so entrenched in the UK, there are parallels in a lack of willingness to engage designers in a strategic role (IDC, 1989).

Despite the challenges, design can be a crucial enabler of innovation performance in SMEs. Current trends in product innovation have blurred the distinctions between the various industrial sectors (IDC, 1989). An effective design promotions strategy/policy can help to improve quality and differentiation, assist creation of world class products and services, improve business efficiency (and productivity and margins), increase revenues, and support increased market share and accelerated growth (CII, 2012). Design is an important means of generating user-centered innovations, and competitiveness for businesses (Brown, 2008; Martin, 2009), but one that is insufficiently used by SMEs in developed and developing countries. Design is also a fundamental building block of innovation, a critical enabler of competitive industry, and a key pole in the construction of 'livable', sustainable and cohesive communities (CII, 2012).

There is a growing awareness of the need for more systematic and methodical inclusion of user experience factors in design (Brown, 2009) - such an orientation is underpinned by design-allied competencies in marketing research, consumer behaviour, technology, anthropology and psychology. Moving towards user-experience based approaches will enhance the role of design companies in shaping strategy (rather than merely informing or executing this), and the growing acknowledgement of the value of interaction and service design is helping the discipline to break free from its traditional craft based roots in India, particularly in urban-industrial locations such as Mumbai and Bangalore.

\section{INFLUENCE OF CULTURE AND IDENTITY ON DESIGN AND INNOVATION PERFORMANCE}

Numerous multinational corporations have attempted to enter the Indian market and have rapidly realised the need to better understand both (a) the Indian consumer, and (b) differing regional cultures if they are to meet the needs and aspirations of an increasingly assertive, active and enlightened consumer market (CII, 2012). Some corporations have recognised that successes elsewhere may not translate directly to success in India. Further, some have acknowledged the role that 'indigenous design' can play in blending local technologies and imported components (and vice versa, unifying local needs and imported technologies) (IDC, 1989).

A key characteristic of India is its cultural pluralism - perhaps not surprising in a nation of such size and history. It is a nation that comprises multiple smaller social groups within a larger society: each maintaining its unique cultural identities, values and practices. Indian culture has been heavily influenced by Dharmic religions (1990), which bring together multifarious traditions, achievements, 
beliefs, religions, values, cuisines and forms of dress in one nation, a nation that is defined by its kaleidoscope of regional cultures. In a zoning exercise established in 1985, India was described as comprising seven cultural zones (South, South Central, North, North Central, East, North East and West). The Indian Ministry of Culture (http://www.indiaculture.nic.in) undertook the configuration and definitional work with the stated goal "to strengthen the ancient roots of Indian culture and evolve and enrich composite national culture". These seven zones reflect the individuality and diversity of India.

Within and across such zones, Indian consumers are starting to display behaviours that have been evolving in advanced capitalist economies: they are becoming more demanding and assertive (Wikström, 1996), confidently pursuing aspirational lifestyle goals. As aspirations change for greater numbers of Indian consumers, design has a potential to facilitate the 'reading' of trends and lead the development of meaningful and sustainable products, thus aiding in driving consumption-led growth. India provides both and an opportunity and challenge for design (Ravi and West, 2016). Diversity (cultural, social and economic) in the range of challenges is so vast that designers must be equipped with appropriate knowledge, skills and flexible learning capacity: these qualities are essential if designers are to enjoy success (Heskett, 2008). Cultural and lifestyle differences - alongside access to technologies and prevailing social conditions - result in forms of demand that can be highly variegated (IDC, 1989). An example here is the bicycle: whilst in developed countries it is uncommon for bicycles to be used to carry loads, in rural India, cyclebased cargo shipment is common. Therefore, designing a bicycle for rural versus urban Indian environments poses different challenges for the designer and manufacturer. Such cultural diversity creates a challenge for design education: the range of design provision and skill sets required by design professionals can be very broad indeed.

To even the casual observer, it is clear that 'craft' is embedded within the culture of Indian design (Finger and Schuler, 2004; McGuirk, 2012). Traditionally craft practices and practitioners have been considered the initiators of design in India. Textiles have been at the heart of this, as they combine craft and design principles (so too they have been at the centre of the transition from rural to urban-based manufacturing). Many design disciplines still refer back to craft practices to understand the skill requirements of designers. Crafts account for 15 to $20 \%$ of the India's manufacturing workforce, and contribute $8 \%$ of GDP in manufacturing. However, craft remains a neglected area in development efforts in India (CII 2012). Responding to local needs through new product innovation is an important requirement (IDC, 1989): craft- based industries have the potential to reinvigorate local (rurally based) trades, occupations that are often abandoned in favour of employment in cities (IDC, 1989). For example, local toy and doll industries with appropriate design and marketing inputs could be used to generate sustainable employment in rural and semi-urban areas. The Confederation of Indian Industry (2012) argues that design has 
the potential to leverage indigenous manufacturing and to encourage exports of labour-intensive manufacturing. However, collaborations are often difficult for small-scale craft based industries. There are examples of success though: one such is the Co-optex initiative with Fabindia, an Indian chain-store retailing garments, furnishings, fabrics and ethnic products that are handmade by approximately 40,000 craftspeople across rural India (Wood, 2011). Collaborating with the National Institute of Design, the partnership helped to combine craft skills (Dastakar craftspeople) with design in order to introduce a new product range that helped to revitalize an ailing the brand.

In France, India and Sweden, consumers frequently favour a design style that is reflective of their unique cultural characteristics, this is often referred to as a reflecting a national design identity (National Design Competitiveness Report, 2008). Previous research (Douglas \& Nijssen, 2002; Suh \& Kwon, 2002; Kelley, 2001; Doyle et al., 1992; Aldersey-Williams, 1992) has established the importance of national design identities in achieving competitive advantage in international markets. Dawson et al. (2005) argue for the importance of regional and national product identities, stating that "the country of origin of a product has a significant bearing on the consumer buying decision". According to the Korea Institute of Design Promotion (2008), Italy is rated as having the world's most effective national design identity. Through international promotion it has achieved recognition of national craftwork skills across a range of sectors, developed the value of design, and massively enhanced national brand equity. 'Make in India' (2014), is a national government programme (launched by the current Prime Minister), that aims to transform India into a global manufacturing hub. Employing Dawson et al's (2005) 'country of origin principles' the programme is designed to promote India as a provider of innovative manufacture. The initiative encourages the use of design innovation to (a) help explore new product development opportunities, (b) support new market creation, (c) trigger go-to-market mechanisms for new ideas, and (d) underpin development of product-service eco-systems.

\section{REFLECTIONS - CHALLENGES FOR THE FUTURE OPTIMISATION OF DESIGN}

Our comparative review of policy and design industry development literatures, and our research with respect to a spectrum of design promotion initiatives, highlighted four complex and interleaving factors/themes that are explicitly (and sometimes more subtly) shaping the contribution of design to the innovation performance of Indian SMEs.

Interviews were conducted with the Chief Coordinator of the MSME Design Clinic scheme from NID, Mr Jitendra Rajput, and regional coordinators, Purindar Dutta and Ashok Mondal. In addition, two designers that are engaged to work on the MSME projects were interviewed. During interviews, issues addressed included: (1) how and why do cultural issues (such as Indian identity, regional characteristics) impact on the role and use of design in India; (2) in what ways and why do urban locations impact on the take-up and use of design; (3) why have specific geographic 
locations (Pune, Mumbai, Bangalore, New Delhi) become key design powerhouses; (4) what skills impact on the adoption and use of design in Indian industry; and, (5) how is India balancing craftbased design, societally-driven design and consumer-driven design? The interview exercise also permitted more profound contextualization of early, literature-based and country-comparison findings, and sensitization to evolving realities of current design-innovation-business relationships in India. The four key themes relate to (a) implications of regional cultures for the take-up of design, (b) influence of ubanisation on the design infrastructure, (c) design education and the alignment of business-design expectations, and (d) changing practices in the application of design (across various sectors).

\section{Impact of regional culture(s) and traditions on the role and use of design in Indian SMEs}

Historically and culturally, the roots of Indian design activities can be found in traditional craft practices (CII, 2012). "latent design" practice emerged from established craft practices that placed emphasis on form and aesthetics. A vast array of different forms of craft products are inextricably linked to the rural economy and its socio-cultural milieu (differentiated according to regional location) (IDC, 2009). At a cultural level, the past and present are linked by craft in India. Some commentators assert that rural crafts constitute a last bastion against loss of identity among various culture groups. Crafts, when understood properly and developed with sensitivity, can connect the rural economy with the modern urban economy to great commercial (and social success). For example, the design-led firm, 'Hidesign' uses full grained leather that is vegetable tanned via traditional methods of soaking hides for 40 days in the extracts of barks and seeds, then hand rubbed with dyes to improve grain visibility and impart a strong and natural look. These traditional high quality materials are then fused with contemporary design skills to produce items, that whilst exclusive, are reflective of an Indian national design identity (Hidesign Australia, 2016). Hidesign embodies the precept of the Design Clinic scheme team that 'crafts are yesterday's innovations and therefore the foundations for tomorrow's innovations'. The Hidesign example provides a powerful pointer to possible future innovating collaborations (ones that fuse tradition with cutting-edge design and techniques). However Mr Dutta and Mr Mondal, regional Design Clinic officers opine that there are currently few well established Indian brands that emanate from traditional practices (unlike Italy that has multitude of global luxury brands that originate from small regional enterprises).

The potential is evident nonetheless. Deep Kapuria, Chairman, CII Trade Fairs Council stated in 2013 that the Indian MSME sector provides excellent opportunities for both self-employment and wage-employment outside the agricultural sector, and that it contributes in building an inclusive and sustainable society in myriad ways via creation of non-farm livelihoods at low cost, providing balanced regional development, enhancing gender and social balance, and delivering environmentally sustainable development. Where craft-based MSMEs are able to fuse traditional 
making skills and materials with strong design sensibilities, both export and aspirational home markets may come within reach.

\section{Impact of Urbanisation on Design Eco-systems in India}

The decline of India's agricultural sectors (in terms of contribution to GDP) commenced in 1941 as the percentage contribution of the secondary sector increased (Sodhi, 1994). In addition to partition-fuelled migration in 1947, economic/productive re-balancing resulted contributed to the rapid growth of the four metropolitan cities of Kolkata, Delhi, Mumbai, and Chennai. During the period up to 1980, with a goal of achieving a self-reliant socialism, the Indian government had adopted centralised planning, restrictive investment strategies and a highly regulated approach to private sector business operations. These policies helped to drive the growth of public sector, which resulted in the rapid development of public transport, roads, water supply, electricity, and rural and urban infrastructure. However, charges of poor productivity in the public sector, alongside political and policy shifts, saw the emergence in the 1990s of private-sector driven growth, diffusion of new technologies, increasing living standards, and increasing wages in urban areas. These socio-economic shifts culminated in the development of a new 5 year plan in 2007, one that focused on leveraging urbanization to drive the further economic development of the nation.

Although design awareness has been seen to be unfolding both in rural and urban contexts, design in India is frequently closely linked with urban ecosystems, wherein it is deployed as a bridge between local craft producers, traditional engineering/manufacturing companies, and new high-tech operators - entities that are often independent of each other. Essentially, the growth of design in India can be linked to urbanization, and the Indian design industry is predominately situated in four key urban centres, namely Bangalore, Mumbai, Delhi and Pune (CII, 2012). The growth of design in these cities is not uniform, though some driver factors are common across the territories.

Bangalore evolved into a manufacturing hub for public sector heavy industries (aerospace, telecommunications, machine tools), space and defence following independence. Its recent success has been due to its focused concentration on software services (enabled via economic liberalization) and the city has become a main home to India's information technology industry. Mumbai, known as the gateway to India, is a major port and its economy in the period up to the 1980's, was heavily based on textiles and shipping. In recent decades (again, following liberalization and encouragement to private enterprise) the city has become a leading finance and IT centre. It has also established itself as a major cultural centre, due in large part to the explosion of Bollywood, and has become a key creative and media centre. Pune is a city known for its manufacturing and automobile industries, and is recognised as a location for prestigious research 
institutes for information technology (IT), education, management and training. These capabilities and expert clusters help to attract migrants, students, and professionals from India, South East Asia, the Middle East, and Africa. Pune is the fastest growing city in the Asia-Pacific region and is ranked $145^{\text {th }}$ in the 'Mercer 2015 Quality of Living' listings. It is also ranked second in India, just behind Hyderabad, on quality of life indicators. Delhi's urbanisation is perhaps less remarkable, as the city has for centuries been a trading centre at the heart of several key trade routes. In recent times, Delhi has benefited from the existence of a large consumer market, the availability of skilled labour, and the presence of a major retail industry. This combination has been important in attracting foreign investment, especially in the consumer market domain.

In addition, these urban areas have industry clusters that are perceived, in general, to be highly receptive to design inputs and to be open to the adoption of design readily, as a result of the close proximity between manufacturing companies, design promotion agencies and design studios. This situation has led to the emergence of 'design hubs' around constellations of sustainable businesses and in existing commercial areas (CII, 2012). Another contributing factor in urban areas has been the role of design education in helping to sensitize industry actors to the benefits of design, and encouraging them to engage with a ready supply of proven design talent. The availability of designers, access to technical personnel, the inception of design initiatives, the availability of design promotional intermediaries, and local demand for 'design-enabled' or designrich products has, in effect, provided fertile ground for the flourishing of urban design ecosystems.

Common to all these centres is that they have brought together (informally and formally) groups of educators, designers, design agencies and industry partners in interconnected and concentrated networks. There is a parallel with the UK here, wherein the design economy has a strong concentration in London and the South East of England (though concentration in the UK is nominally organic rather than deliberate) (Design Council, 2015). In India, the explosion of mobile broadband has driven the growth in media and graphic design disciplines (CII, 2012). Delhi leads in terms of having the greatest number of firms offering graphic design services, closely followed by Bangalore and Pune. Whilst the case for clustering of design businesses is strong, it can also be suggested that concentration is to the disadvantage of businesses located in tier 2 and tier 3 cities. Enterprises in these zones have little proximal design provision and experience difficulty in engaging with design companies (and thus, in appreciating the utility of design) (CII, 2012).

Pune and Bangalore (CII, 2012) have become the design powerhouses of India. They can both attribute success in part to their ability to: (1) attract qualified design entrepreneurs (such workers settle as they perceive a freedom to operate in favorable conditions and enjoy access to physical infrastructure); (2) create networks of like-minded entrepreneurs, and (3) provide an affordable and high quality lifestyle. In addition both cities have also maximised their pre-existing industrial 
clusters and are well connected with other main centres in India. According to Jitendra Rajput, Chief Coordinator of the MSME Design Clinic scheme, these locations have become "obvious choices for designers...to set up their design studios". Mumbai and New Delhi - the traditional economic powerhouses of the country - can offer some benefits, but lack the lifestyle elements. Ahmedabad and Jaipur are aiming to share the mantel as India's new economic and productive centres, and aspire to match the success of Pune and Bangalore as design centres. Of course, each of these cities is a Tier 1 location. This raises the question (as noted above) of the prospects for design-innovation-business coordination in tier 2 and 3 locations - the question remains, will they benefit from trickle-down or find themselves out in the cold?

\section{Design education and skills, and misalignment of visions and expectations}

There is general agreement that India has a dearth of 'good' designers. There is also concern that the regions have a lack of capacity to produce appropriately trained graduates, and further that the expectations of existing designers are frequently unfulfilled. Most $\mathrm{Cl}$ professionals primarily wish to see their products reach and become successful in the market. However, even though many ISMEs undertake design-led innovation projects (under the aegis of design development programmes), only a small proportion of assignments are currently implemented (Design Manifesto, 2014). For example, the engagement of designers via design clinic schemes has been something of an experiment for Indian micro, small and medium enterprises (MSMEs). Hence not all projects lead to successful interventions. Whilst awareness of the potential of design is raised amongst MSME leaders, there is frustration for designers as their efforts are appreciated but ultimately shelved. Other incompatibilities and mismatches are in evidence. At present the payment and credit systems of ISMEs is incompatible with designers' expectations and requirements. In addition, difficulties exist in aligning the aspiration of ISME leaders with that of designers and with Design Clinic Scheme (DCS) objectives (CII, 2012). Unfulfilled expectations are creating dissatisfaction for ISMEs, as the latter accuse designers of 'overselling' quality. Clearly, improved communications and alignment of expectations is required.

\section{Practices and applications re: design in traditional and contemporary manufacturing}

Some (enlightened and engaged) ISMEs are gradually recognizing the importance of design. Whilst most understand its role in relation to cosmetic changes (frequently applied at a later stage of the product development process), only a few comprehend the notion of design as a step-wise process and strategy (Brown, 2008). There has been an increase in awareness and receptiveness since the implementation of the DCS, however this impact is still too small to facilitate realistic measurement. DCS has been evaluated overall as a success, and there is clear evidence of gains for all parties. One finding is that various MSME sectors confront different challenges in the incorporation of design, however, research-intensive and engineering based manufacturers (medical devices, machines tools etc.) appear well-attuned to design-collaboration and have been 
major participants. Some SMEs have moved towards engagement with design at more fundamental levels or earlier stages of the product and process life-cycle, though have recognized the importance of strategic design based interventions (Acklin, 2010).

\section{CONCLUSIONS: OPTIMISING DESIGN FOR ISMES}

This paper set out with three key aims: first, to review evidence from an international perspective on the factors that can influence the contribution of design to innovation performance at enterprise and national level; second, to examine the role of design support initiatives in delivering enhanced competitiveness (especially in the contemporary Indian context); and third, to examine the implications of cultural diversity, demographics, and regional identity for design-facilitated innovation in Indian SMEs

We can conclude that - from a global perspective - design is recognized as an extremely valuable strategic asset at the highest levels of some of the world's most successful corporations. So too, the utility of design processes are recognized increasingly in progressive and enlightened SMEs. Governments in both advanced and developing economies are eager to highlight design (acknowledging its contribution to growth, GVA and exports), and to this end, many are actively engaged in data collection re: design's impact on trade, and in the roll-out of a range of designpromoting initiatives. Indeed, it can be argued that the international profile of design has never been so strong.

If it can be agreed then, that 'good' design is a desirable asset for any country, sector and enterprise (and for social development too), how might it be possible to optimize the application and embedding of design in the Indian context? India is experiencing rapid growth, and design is just one factor that will facilitate its acceleration. However, it is a factor that faces a unique set of challenges - some highlighted in existing initiatives and some suggested by a survey of developmental activities in parallel economies. First, the orientation to design that is prevalent in India (importation and adaptation) must gradually shift in favour of indigenous design. Second, there is much space to blend traditional craft with contemporary design sensitivities - indeed, India with its rich heritage and culture is uniquely well-placed here. Third, concentration of design, whilst understandable, may starve SMEs in non-primary cities of design-enabled innovation. Fourth, design education is worthy of investment - ensuring that such training is relevant and future focused is essential. Fifth, promotional initiatives must be smart and targeted - raising profile for design, providing innovation success examples, and ensuring alignment of visions (between SME leaders and designers) can lead to greater take-up. Sixth, intelligent and responsive policy can provide an environment in which design can flourish: ensuring that measurable outcomes are in place, and that data is collected systematically will assist in sustaining appropriate policy actions. 
With attention to these factors, the future for design in India is a bright one - the challenges are not insurmountable and the potential benefits of increased use of design are enormous. The rich cultural heritage of the nation offers unique opportunities for development - it is to be hoped that currently developed nations will presently be casting their gaze to India for lessons in the optimization of design-enabled innovation performance. 


\section{REFERENCES}

Acklin, C. Design-Driven Innovation Process Model. Design Management Journal, 5(1), (2010): 5060.

Aggarwal, S.K and Nath, V, Urbanization, Urban Development, and Metropolitan Cities in India. Concept Publishing Company. 2007: 6. ISBN 978-81-8069-412-7

Alpay Er, H, Development Patterns of Industrial Design in the Third World: A Conceptual Model for Newly Industrialised Countries, Journal of Design History, Vol. 10, No. 3 (1997): 293-307

Arawati, A., Barker, S., and Kandampully, J."An exploratory study of service quality in the Malaysian public service sector", International Journal of Quality \& Reliability Management, Vol. 24 Iss: 2 (2007): $177-190$

Bolton, S. and Green, L. 'Maximising the Value of Product Design Innovation: Re-framing and Realiging the Business-Design Relationship' Economia Creativa, No1, issue 2 (2014)

Bolton, S.M., Improving Product Design and Development Performances in SMEs with User Centred Design Activities, Business School/ Centre For International Business And Innovation The Manchester Metropolitan University, UK, (unpublished PhD thesis), 2013.

Bonsiepe G, Development through Design - A working paper prepared for UNIDO at the request of ICSID, UNIDO, United Nations Industrial Development Organisation, Vienna, (1973).

Brown, T., Design Thinking. Harvard business review, 86(6), (2008): 84-93.

Brown, T. Change by Design: How Design Thinking Creates New Alternatives for Business and Society. Harper Collins: New York, 2009.

CISAC, 'The Creative Industries + BRICS: Review of the State of the Creative Economy in Brazil, Russia, India and China', International Confederation of Societies of Authors and Composers [CISAC], 2014.

Chiu, M.L. "An organizational view of design communication in design collaboration", Design studies, Vol. 23, No. 2, (2002): 187-210.

Choi, Y., A Comparative Study of National Design Policy in the UK and South Korea. Lancaster: Lancaster University, (unpublished PhD thesis), 2009.

Competition Commission of India, Annual Report 2013-14, www.cci.gov.in, 2014.

Confederation of Indian Industries, "Government Incentives and Schemes for Micro, Small and Medium Enterprises (MSMEs) Towards Export Promotion”. Ministry of Micro, Small and Medium Enterprises, Government of India. May, 2012.

Confederation of Indian Industry, Indian Design Report, 2012.

Cox, G., 'The Cox Review of Creativity in Business'. Report for HM Treasury, UK, 2005.

Crawley, A., "Tackling business issues through design: finding new routes to old problems", Design Council, UK, 2015.

Danish Design Centre, The Economic Effects of Design, National Agency for Enterprise and Housing, 2003. 
Dawson,K.; Larsen,P.; Cawood,G.; Lewis,A., National Product Design Identities, in: Creativity and Innovation Management, Vol. 14, N. 4, (2005): 393-404, Blackwell Publishing, UK, available at http://onlinelibrary.wiley.com/doi/10.1111/j.1467-8691.2005.00359.x/pdf (accessed 17 Mar 2011).

Department for Culture, Media and Sport, 'Creative Industries Mapping Document 1998', DCMS, HM Government, UK, 1998.

Department for Culture, Media and Sport, 'Creative Industries Mapping Document 2001', DCMS, HM Government, UK, 2001.

Design Council, “Design for Innovation”, Design Council, London, 2011.

Design Council, 'Designing Demand National evaluation 2007-2012', Eden Partners, 2012.

Design Council, "The Design Economy: The value of design to the UK economy", Executive summary. Design Council, London, 2015.

Development Commissioner, "Guidelines - Design Clinic Scheme for Design Expertise to MSME Sector", Government of India, Ministry of Micro, Small and Medium Enterprises, New Delhi, 2010 [http://designclinicsmsme.org/wp-content/uploads/Guideline-DC-MSME07-05-2010.pdf]

Do Patrocinio, Gabriel Henrique Torres, "The Impact of European Design Policies and Their Implications on the Development of Framework to support Futrue Brazilian Design Policies", Unpublished PhD Thesis, Cranfield University, UK, 2013

Douglas, S. and Nijssen, E.J., On The Use Of 'Borrowed' Scales In Cross-National Research: A Cautionary Note, New York University, New York, 2002.

Doyle, P., Saunders, J. and Wong, V., Competition in global markets: a case study of American and Japanese competition in the British market, Journal of International Business Studies, Vol.23, No.3, (1992): 419-442.

Finger, J.M. and Schuler, P. eds., Poor people's knowledge: promoting intellectual property in developing countries. World Bank Publications, 2004.

Florida, R.L., The Rise of the Creative Class: And how It's Transforming Work, Leisure, Community and Everyday Life, Basic Books, New York, ISBN 0465024769, 2002.

Frawley, D, From the River of Heaven: Hindu and Vedic Knowledge for the Modern Age, Berkeley, California: Book Passage Press, ISBN 1-878423-01-0, 1990

Furniss, L., 'Beyond Discipline: Design Practice and Design Education in the $21^{\text {st }}$ Century', Report for Strategic Creativity Research Lab, Birmingham City University, 2015

Green, L., Cox, D., and Bitard, P. Design as a Tool for Innovation. In Cox, D., Rigby, J. (Eds) Innovation Policy Challenges for the 21st Century. Routledge, London, 2012.

Heskett, J., Creating Economic Value by Design. International Journal of Design, 3(1), (2008): 7184

Hidesign Australia, "About Us", < http://www.hidesignaustralia.com.au/\#!about us/c1se> (Accessed: 26 May 2016)

IIT, 'Design Manifesto', The Department of Design at IIT-Hyderabad, 2014.

Indian Design Council, 'Design as a Strategy for a Developing Economy' IDC, IIT Bombay (originally published in 1989 and updated 2009), 2009. 
Lee, S., Design Policy and Global Network: World Design Forum Proceedings. Seoul: KIDP and ICSID, 2002.

Lundvall, B. Å. (ed.), National Innovation Systems: Towards a Theory of Innovation and Interactive Learning, Pinter, London,1992.

McGuirk, J. "How will India design its new identity?"

<https://www.theguardian.com/artanddesign/2012/mar/15/india-design-identity-forum-new-delhi>

(Accessed: 26 May 2016), 2012.

Maguire,P.J. and Woodham,J.M. (eds.), Design and Cultural Politics in Postwar Britain, Leicester University Press, London, 1997.

Martin, R.L, The design of business: Why design thinking is the next competitive advantage. Harvard Business Press, 2009.

Mercer, Quality of Living Survey; http://www.uk.mercer.com/newsroom/2015-quality-of-livingsurvey.html, 2015.

Moultrie, J., and Clarkson, P.J., and Probert, D. ,'A Tool to Evaluate Design Performance in SMEs'. International Journal of Productivity and Performance Management. 55 (3/4), (2006): 184 216.

National Design Competitiveness Report, Korean Institute of Design Promotion, 2008.

National Skill Development Association, “Empowerment through Skill Development”, 2014.

Planning Commission, Government of India, Eleventh Five Year Plan (2007-2012) - Inclusive Growth, Volume 1, Oxford University Press, New Delhi, ISBN-13: 978-0-19-569650-9, 2008.

Pradhan, R.P., "Does infrastructure play role in urbanization: evidence from India". Indian Journal of Economics and Business, (2007): 81-92

Ravi, S. and West, D. M., "Building a Design Economy in India", Brookings India, 2016

Suh, T. and Kwon, I., Globalisation and reluctant buyers, International Marketing Review, Vol.19, No.3, (2002): 663-680.

Throsby, David, Economics and Culture. Cambridge University Press, Cambridge, 2001.

Topalian, A., Promoting design leadership through skills development programs. Design Management Journal (Former Series), 13(3), (2002): 10-18.

UK Government's Department of Culture, Media and Sport, 2001.

UK Government's Department of Culture, Media and Sport published the "Creative Industries Mapping Document, 1998.

UNCTAD, Creative Economy Report 2004 - United Nations Conference on Trade and Development. United Nation, 2004.

UNESCO, Framework for Cultural Statistics, available at:

http://www.uis.unesco.org/culture/Pages/cinema-data- release-2011.aspx, 2009

UNIDO and UNESCO 'Creative Industries and Micro \& Small Scale Enterprise Development: A Contribution to Poverty Alleviation'. Project XP/RAS/05/002 
Velloso, J. P. d. R., O Brasil e a economia criativa: um novo mundo nos tropicos (Brazil and creative economy: a new world on the tropics, (2008): 599, Rio de Janeiro: Jose Olympio Editora. (in Portuguese).

Wikström, S., Value creation by company-consumer interaction. Journal of Marketing Management, 12(5), (1996): 359-374.

Wood, S., Sustaining crafts and livelihoods: handmade in India. craft+ design enquiry, 3, (2011).

World Economic Forum, The India Competitiveness Review 2009, Confederation of Indian Industry, 2009.

World Economic Forum, The Global Competitiveness Report 2009-2010

i The authors wish to extend their thanks to the anonymous reviewers of this paper, and to the editors of the Special Issue. We are immensely grateful for the thoughtful, considered and constructive comments that have ensured very significant improvement of the document. Any errors that remain in the paper, are of course, the responsibility of the authors alone.

ii Note on Methodology and Approach: this paper contains both theoretical and empirical components, the latter designed primarily to provide verification and validation of some of the themes and findings set-out in the text. The main body of the work was constructed on the basis of an exhaustive review of relevant academic, policy and practitioner/industry literature relating to the contribution of design to firm and sectorlevel innovation performance. This review has a strongly comparative orientation: we examine the international picture as this has developed over the past fifty years, and track the evolution of some of the key ideas that link design with industrial and economic performance. Beyond this mapping, we focus more directly on the development of thinking (and related policy and industry level responses) in the UK and Indian contexts. Of course, the UK has an established record of data collection with respect to the design sector's inputs to (and impacts on) manufacturing - and more recently services-sector - production and consumption. This data has provided a rich resource for researchers, policy-makers and design practitioners, and we timeline trajectories in theorising and policy-development as these are reflected in industry and design-sector promotional agency reports, the writings of design commentators, contributions in academic journals, and in government sponsored publications. This approach is mirrored in relation to the Indian design sector: whilst there is perhaps less material available here (given relative maturity of the industry), there remains much useful information that can be surveyed. In the case of both comparator countries, the researchers (a) deployed their own knowledge of sources (applying standard bibliographic trawl and select techniques), and (b) engaged with a range of design, academic and policy sector experts to construct a comprehensive map of available and relevant resources. This engagement was particularly effective in surfacing relatively new and grey/industry-internal materials. In addition (and subsequent to), the comparative review, the authors were eager to test some provisional ideas and theories with high-level and expert design sector professionals: this was thought to be particularly important in the fast-developing but highly dispersed Indian design-industry context. To facilitate the harvesting of views, the researchers engaged directly with five expert members of the Indian 'Design Clinic Scheme' Team. This engagement was extremely helpful in refining ideas and in contextualising, nuancing and enriching both India-UK comparisons, and the paper's overall findings. Each of the experts was asked to comment on the five core themes covered in the paper, and their inputs have ensured that the research and its conclusions more adequately reflect evolving realities in the contemporary Indian context.

iii India Design Mark - Celebrating Good Design: development of a system to identify good design becomes an imperative. It is envisaged that in the long run the India Design Mark will serve as a measure that not only provides better products to the Indian consumer, but will also be a major enabler in helping brands become global as 'Made in India' is supplemented with 'Designed in India'. Provision of the 'India Design Mark' (IMark) was initiated by the India Design Council to celebrate good design and to promote the competitiveness of Indian industrial design products. 